\title{
Prevention of 90-day Detox Readmission for Opioid use Disorder by A Community-Based Life-Changing Individualized Medically Assisted Evidence-based Treatment (C.L.I.M.B.) Program: A Quasi-Experimental Design
}

Zhehui Luo ( $\sim$ zluo@msu.edu )

Michigan State University

\section{Canopy Roychoudhury}

Blue Cross and Blue Shield of Michigan

William S. Pompos

Blue Cross and Blue Shield of Michigan

James DiMaria

Blue Cross and Blue Shield of Michigan

Cynthia Robinette

Blue Cross and Blue Shield of Michigan

Purva Gore

Blue Cross and Blue Shield of Michigan

\section{Rohon Roychoudhury}

Michigan State University

\section{William Beecroft}

Blue Cross and Blue Shield of Michigan

\section{Research Article}

Keywords: Opioids and substance-related and additive disorders, community integration and recovery-oriented care, mental health care/service delivery systems, rehabilitation

Posted Date: February 4th, 2022

DOI: https://doi.org/10.21203/rs.3.rs-962685/v2

License: (c) (i) This work is licensed under a Creative Commons Attribution 4.0 International License. Read Full License 


\section{Abstract}

Background: Evidence for community-based detox readmission prevention strategies for opioid use disorder (OUD) is scant. We evaluated a pilot program designed to provide individualized and structured treatment plan, including addressing prolonged withdrawal symptoms, family/systems assessment, contingency management, and medically assisted treatment.

Methods: A non-randomized quasi-experimental design was used to compare the pilot sites (treatment) and comparison sites before and after the program started, i.e., a simple difference-in-differences (DID) strategy. Adults 18 years and older who meet the Diagnostic and Statistical Manual of Mental Disorders version 5 criteria for OUD and had a detox admission at any OUD treatment facility in two study periods between 5/2018 and 12/2019 are included. Readmission for detox in 90-days after the initial detox was the primary outcome. Multiple statistical estimation methods were used to adjust for potential confounding factors between treatment and comparison groups.

Results: A total of 2,320 unique patients with 2,443 initial detox admissions in the pre- and post-periods were compared. Compared with the comparison patients, the C.L.I.M.B. patients had higher readmission in the pre-period (unadjusted readmission rates $16.4 \%$ vs. $10.0 \%)$, but similar rates in the post-period (11.8\% vs. $10.1 \%)$ after the implementation of the pilot program. For the primary outcome 90-day readmission, all DID estimates were not statistically significant (adjusted estimates ranged from 6.0 to 17.3 percentage points difference favoring the C.L.I.M.B. program). For the secondary outcomes of service utilization, the C.L.I.M.B. program had reduced the proportion of patients using the intensive outpatient treatment compared to the comparison group and the statistically significant DID estimates ranged from 13 to 18 percentage point differences for the intensive outpatient treatment.

Conclusions: Treating OUD as a chronic condition instead of an acute episodic condition for patients in the community is feasible and has a potential to reduce intensive outpatient services. Although the small sample size of the pilot program precluded us to draw a definitive conclusion, we believe more OUD treatment facilities should work with health plans to standardize care for patients with OUD and promote lowering readmission for inpatient withdrawal management.

\section{Introduction}

Almost 500,000 Americans died from an opioid-related overdose between 1999 and 2019 and the age-adjusted synthetic opioid-involved death rate increased $15 \%$ from 9.9 to 11.4 per 100,000 population. ${ }^{1}$ The use of inpatient addiction treatment, though lacks efficacy support, ${ }^{2}$ increased from 38\% in 2004-2008 to 52\% in 2009-2013 among individuals who received treatment for opioid use disorder (OUD) in the prior 12 months, ${ }^{3}$ and the rates of opioid-related detoxification discharge decreased from 31.5 to 27.4 per 100,000 persons between 1993 and 2016. ${ }^{4}$ Evidence-based strategies - including reducing opioid prescribing and increasing access to treatment of OUD - must be adapted and deployed together to address the crisis and save lives. ${ }^{5}$ In the past few decades, OUD has been treated on an episodic basis with poor outcomes and high relapse rates. Many patients and providers lament the mismanagement of OUD, especially the lack of "ownership" in handling the tapering process. ${ }^{6,7}$ Methadone, buprenorphine and naltrexone have been shown to prevent relapse in clinical trials, 8,9 however in 2016 only $36 \%$ of substance use treatment facilities with outpatient services offered any medication treatment (buprenorphine $25 \%$, naltrexone $21 \%$, methadone $10 \%)^{10}$ and in California only $11 \%$ of all detoxification episodes were followed by maintenance treatment within 14 days in $2012 .{ }^{11}$ Not all treatment facilities can meet the special needs by patients with histories of unemployment, homelessness, and psychiatric comorbidities that require social service interventions not usually found in the medical system. ${ }^{12,13}$ The American Society of Addiction Medicine (ASAM) recommends the OUD treatment choice be based on a shared decision making process. ${ }^{14,15}$ Strategies specifically designed for relapse prevention and withdrawal management are equally important for this chronic relapsing disease. ${ }^{16}$

Grounded in the community-based chronic care model, a pilot program (Community-based Life-changing Individualized Medically assisted evidence-Based treatment, [C.L.I.M.B.]) was implemented on May 1 and Dec 1, 2018, by the Blue Care Network (BCN) and Blue Cross Blue Shield (BCBS) of Michigan respectively, for individuals 18 years and older who met the

Page 2/20 
Diagnostic and Statistical Manual of Mental Disorders version 5 criteria for OUD and were admitted to inpatient detox at two sites. This paper evaluates the impact of the program on detox admission prevention in 90 days after discharge from inpatient facilities. The question is: If the C.L.I.M.B. program is rolled out to sites like the pilot sites will it reduce 90-day readmission among OUD patients?

\section{Methods}

\section{Design}

Consistent with the quasi-experimental two-group pre-post design, we used the difference-in-differences (DID) method to ameliorate potential confounding bias. ${ }^{17,18}$ The underlying assumption of the DID method is that the change in readmission rates from pre- to post-period in the comparison group is a good proxy of the counterfactual change in the pilot group had there been no pilot program (Figure S1 in supplemental materials). The effect of interest is the average treatment effect on the treated which answers the question: for patients treated in the pilot sites, was the program a cause for the change in readmission rate? On the probability scale, a DID method estimates the difference of risk differences (DRD); and on the odds ratio (OR) scale, a DID method estimates the ratio of ORs (ROR). The pre-and post-periods for the BCN (a health maintenance organization [HMO]) patients were $7 / 1 / 2016$ to $4 / 30 / 2018$ and $5 / 1 / 2018$ to $8 / 31 / 2019$; the corresponding periods for the BCBSM (a preferred provider organization [PPO]) patients were $2 / 1 / 2017$ to $11 / 30 / 2018$ and 12/1/2018 to $3 / 30 / 2020$. In the post-period, another site (Brighton Center) implemented a program like C.L.I.M.B.; thus, to avoid contamination, patients whose initial detox occurred at that site in the post-period were excluded (Figure 1). The pilot program was approved by the BCN and BCSM medical directors, and the current evaluation was approved by the Institutional Review Board of Michigan State University as non-human subject research (STUDY00000846).

(Figure 1 Here)

\section{Patients}

Patients 18 years or older, who had a detox inpatient stay for a diagnosis of OUD in any of the two pre-periods were included in the study. To ensure data completeness, a patient had to be enrolled in the health plan for 6 or more months before the initial detox in the pre-period to capture baseline comorbidity; and the initial detox did not occur within 90-days of each period's end date.

\section{Intervention}

Following ASAM guidelines, ${ }^{14,15}$ the C.L.I.M.B. program (Figure S1) included services for the continuum of OUD cycle, including detoxification, residential services, partial hospitalization/intensive outpatient services, outpatient services with medically assisted treatment (MAT), and a modified smartphone support application (app), called A-CHESS, originated in 2011 at the University of Wisconsin Center for Health Enablement Support System (CHESS), which is a comprehensive relapse prevention tool based on the self-determination theory ${ }^{19}$ to help patients with substance use disorders (SUDs) succeed in recovery.

Prior to the pilot program implementation, providers in the two sites provided same services as other OUD treatment facilities. During the implementation, they agreed to follow the C.L.I.M.B. codified protocol (detailed in Appendix A) with an emphasis on the master-treatment-plan development, family/system assessment, warm handoff, completion of tasks regardless of length of stay, and the use of A-CHESS. Key features of A-CHESS ${ }^{20}$ included :1) a "Help" button linked to the patient's preapproved supporters, 2) positive and potentially distracting games, and audio-video relaxation recording; 3) cognitive behavioral therapy boosters; 4) functionality monitoring with self-assessment tools; 5) a global positioning system location tracker that will 
initiate a patient-defined action (e.g., contacting sober coach) when s/he approaches a high-risk location, and 6) just-in-time feedback via a counselor dashboard.

\section{Comparison Group}

All other OUD treatment facilities in the U.S. that BCBSM and BCN members attended for inpatient detox in the study period constituted the comparison group. The usual care available at each facility varied and was expected to be representative of current practice in the field. Not all facilities covered the continua of LOCs.

\section{Main Measures}

Primary outcome: 90-day detox readmission after an initial detox inpatient stay at any facility. Readmission was identified by the same method as the initial detox: any inpatient stay with a diagnosis of F11.x or F11.xx using the International Classification of Diseases, $10^{\text {th }}$ version, Clinical Modification (ICD-10-CM) codes, and revenue codes $01 \times 6(x=1,2,3,4$, or 5$)$.

Secondary outcomes: Other ASAM LOCs, including partial hospitalization/intensive outpatient services, outpatient services and MATs. MATs were identified using National Drug Codes in pharmacy claims and the Current Procedural Terminology codes; and revenue codes and/or procedure codes were used to find LOC 1.0-2.5 (partial hospitalization/intensive outpatient services/outpatient) services (list of these codes available upon request).

Treatment groups: the National Provider Identifier codes for the two pilot facilities were used to identify patients in the pilot group. Patients in the other treatment facilities were the comparison.

Comorbidity: the Agency for Healthcare Research and Quality Clinical Classification Software Refined version (v2021.2) ${ }^{21}$ based on the ICD-10-CM codes was used to find in medical claims of comorbid conditions in the 6 months prior to the initial detox in each period, including mood disorders; anxiety-, fear-, trauma- or stressor-related disorders; alcohol-, cannabis-, sedative-, stimulant- hallucinogen- or inhalant- related disorders; neoplasms; suicidal ideation/attempt or intentional selfharm; endocrine, nutritional and metabolic diseases; diseases of the nervous, circulatory, respiratory, digestive, musculoskeletal system, or genitourinary systems. Emergency room visits in the 6 months prior to the initial detox in each period were identified using revenue codes $045 x(x=0-9)$.

Covariates: Patient's age, sex, HMO or PPO plan types, and residential zip codes were extracted from health plan enrollment files. The 5-digit zip codes were linked to the census tracts using the U.S. Department of Housing and Urban Development zip code crosswalk files ${ }^{22}$ where a census tract with the highest residential ratio was chosen when multiple tracts were within the same zip code. ${ }^{23}$ Past research found that living in a disadvantaged neighborhood was associated with worse health conditions and increased healthcare utilizations. We used the 2018 Area Deprivation Index (ADI), ${ }^{24,25} 2015$ Childhood Opportunity Index (COI), ${ }^{26}$ and 2018 Social Vulnerability Index (SVI) ${ }^{27}$ to approximate the neighborhood characteristics and as proxies to patient socioeconomic status. Higher ADI rankings and SVI scores indicate more disadvantaged neighborhoods; but higher $\mathrm{COI}$ scores indicate more opportunities. All indices were transformed to have a range from 0 to 100.

\section{Analytic Approach}

We compared the differences in covariates and comorbidities between the C.L.I.M.B. and comparison group in the pre- and post-periods using chi-square tests for categorical variables and t-tests for continuous variables. As in the tradition for propensity score analysis, we also presented the standardized differences (difference divided by the pooled standard deviation) between the two group. When the absolute value of the standardized difference is greater than 0.1 , it is indicative of non-negligible difference. ${ }^{28}$ We estimated the DID effects using six statistical methods to triangulate evidence: 1) multivariable logistic regression adjustment (RA) controlling for comorbidities and covariates; 2) augmented inverse 
probability weighted (IPW) estimation ${ }^{29}$ where covariates for the outcome and the propensity scores (PS) models were selected using logistic lasso; ${ }^{30} 3$ ) IPW estimation where the PS was estimated using logistic regressions controlling for the same covariates in the RA model; 4) IPW-RA double robust method; ${ }^{31}$ 5) bias-corrected single nearest neighbor matching method $^{32}$; and 6) PS matching with a caliper 0.2. The $95 \%$ confidence intervals $(\mathrm{Cl})$ were estimated using the percentile-based bootstrap $\mathrm{Cl}$ with 1,000 bootstrapped samples. All analyses were performed in Stata version $17 .{ }^{33}$

\section{Sensitivity Analyses}

We performed two sets of sensitivity analysis. First, we excluded 123 patients ( 236 admissions) who were in both pre- and post-periods, because the analyses may be contaminated by the correlations between observations for the same patients, especially when the patient was in different treatment groups across periods. Secondly, many randomized controlled trials (RCTs) include stringent inclusion/exclusion criteria. We applied some of the patient-selection criteria of the MAT + A-CHESS trial $^{20}$ that can be defined using our data to assess the robustness of the main-analysis estimates in a selected subpopulation who had no acute medical problems with immediate inpatient treatment needs, no history of psychotic disorders, and not pregnant.

\section{Results}

A total of 2,320 unique patients with 2,443 detox admissions in the pre- and post-periods were included in the main analyses. Table 1 shows that in the pre-period, C.L.I.M.B. patients were more likely to be in the HMO plans, had more mood disorders, and diseases of the musculoskeletal system than patients in comparison sites; however, in the post-period, C.L.I.M.B. patients had fewer other substance-related disorders, or diseases of the nervous or digestive systems than patients in the control sites, mainly due to increased prevalence of these condition in the control group. The largest and most significant differences between the groups were at the neighborhood level. C.L.I.M.B. patients were more likely to live in one the 100 largest metropolitan areas, had lower ADI, higher COI, and lower SVI scores, i.e., they were from relatively more well-to-do neighborhoods.

Before using the PS for adjustments, the raw standardized differences (Table 2) showed consistent patterns as in Table 1. After weighting, the standardized differences were reduced to less than 0.1 for all except for 4 variables (mood disorder, disease of the musculoskeletal system and connective tissue, living in one of the 100 largest metropolitan areas, and mean SVI minority/language score, Table 2 column 2) in the pre-period; however, weighting did not improve balance in the postperiod (17 variables had standardized difference greater than 0.1 , Table 2 column 4 ). The residual imbalance was adjusted using these 4 and 17 variables in the nearest neighbor matching method. The few variables selected by the logistic lasso generated a bi-modal PS distribution (Figure 2) but there was good overlap between the PS of C.L.I.M.B. and comparison groups.

(Figure 2 Here)

All six methods (Table 3) gave similar estimated DRDs and RORs between groups over time. Before the pilot implementation, C.L.I.M.B. patients had statistically significantly higher 90 -day readmission rates than comparison patients $(16.4 \%$ vs. 9.3 to $11.6 \%$ estimated by various adjustment methods); however, after the pilot implementation, readmission rates decreased significantly in the C.L.I.M.B. group to $11.8 \%$ whereas the adjusted rates in controls did not change significantly (varying from $11.1 \%$ to $23.1 \%$ ). The DRDs and RORs were not statistically significant (adjusted DRDs ranged from 6.0 to 17.3 percentage points favoring the pilot group). Compared with that in the pre-period, patient profiles changed a little in both groups, although the changes were not statistically significant in the C.L.I.M.B. group due to small sample size (Table S1 in supplemental materials). The two sensitivity analyses ( $\mathrm{N}=2,197$ observations in Table $\mathrm{S} 2$ and $\mathrm{N}=2,121$ observations in Tables S3) led to results qualitatively the same as the main analyses. 
For the secondary outcomes of service utilization, we found the C.L.I.M.B. program had reduced the proportion of patients using the intensive outpatient treatment compared to the comparison group (Table 4), but the proportions of MAT and outpatient treatments remained stable. The DID analysis using the same methods above showed statistically significant DRDs ranging from 13 to 18 percentage point differences for the intensive outpatient treatment (Table 5).

\section{Discussion}

The ASAM criteria advocate for individualized, assessment-driven treatment and the flexible use of services across a broad range of care, which can be offered by single or multiple providers with "(1) seamless transfer between levels of care, (2) philosophical congruence among the various providers of care; and (3) timely arrival of the patient's clinical record at the next provider." ${ }^{34}$ The C.L.I.M.B. program was designed using these principles. Although there was a significant decrease in 90-day readmission rates in the C.L.I.M.B. group from 16 to $11 \%$ from the pre- to post-period, the DID estimates compared with a community control group were not statistically significant. The program did reduce intensive outpatient treatment compared to the control group, which reflected the guiding principle for continued management of withdrawal in a lower LOC.

There is limited literature on the impact of a community-based OUD chronic care model on reducing detox readmission after the initial detox discharge. In a commercially insured population in the U.S., those entering initial care in an inpatient setting with only short-term inpatient stay without medication for opioid use disorder (MOUD) had a $4 \%$ overdose rate and $74 \%$ allcause rehospitalization in one year; and from 2011 to 2017 there was a significant decrease in overdose rate but no change in all-cause rehospitalization. ${ }^{35} \mathrm{~A}$ small retrospective study in an urban academic hospital found that in-hospital initiation of opioid agonist treatment (OAT) through a hospital-based SUD consultation-liaison team did not reduce 180-day all-cause rehospitalization compared with usual care. ${ }^{36}$ However, a large RCT among eligible medical/surgical patients in the same setting with a more comprehensive patient-navigation service led to lower incidence of all-cause readmissions in 30-, 90-, 180and 365-days, but no significant difference in positive urine drug test. ${ }^{37}$ The above studies suggest treating OUD on an episodic basis without integration in all levels of care is unlikely to reduce readmission related to detox.

Several reasons may explain our largely null findings. First, the pilot program aimed to recruit 300 patients in the program, however, fewer than 200 patients enrolled. Although the program continues in operation, current evaluation was limited to the 16-month period after the program initiation. The lack of power was the main reason why the DID effects were not statistically significant.

Second, one of the key components of the pilot program was the integration of the smartphone app A-CHESS to the clinical practices. Unfortunately, few patients used A-CHESS after they signed up on the phone at discharge (confirmed by the ACHESS data) and providers' feedback suggested that other apps existed with features that patients preferred. In December 2018, the Food and Drug Administration cleared the first smartphone app, reSET-O, to be used alongside the MAT to help improve retention in an outpatient setting. A group of Yale experts also developed a free app, BUP Home Induction, as a companion to MAT. Compared with these tools, the A-CHESS suffers from a few shortcomings. It is not free, and it does not provide the feedbacks that are salient to the patients, e.g., the money saved due to abstinence. Like many apps, systematic evaluation of the efficacy of A-CHESS for OUD is needed. ${ }^{38}$

Third, the pilot program was implemented in the height of the opioid epidemic when many SUD facilities were undergoing changes in practice. While the pilot sites had all ASAM LOC services, the control sites may vary cross-sectionally and over time. The National Survey of Substance Abuse Treatment Services (NSSAT) data showed that the proportion of SUD facilities in the U.S. that offer MOUD increased from 10\% in 2007 to $36 \%$ in $2016 .{ }^{10}$ In a secret shopper audit study in 2019 Beetham et al. found $29 \%$ of residential treatment programs offer OAT. ${ }^{39}$ Using the 2016 and 2019 NSSAT data, we found that the percent of facilities that offered a broad range of services, including partial hospitalization/intensive outpatient services, outpatient detoxification, outpatient methadone/buprenorphine maintenance, and maintenance with medically supervised withdrawal had increased from $15 \%$ in 2016 to $21 \%$ in 2019. Hence, the control sites may be experiencing improvements in services in the study period. Because we did not have the linkage to control facilities in our analyses, we had no good description on the type 
of services they provided. Through our connection with the providers in one large facility (Brighton Center), we knew they initiated a similar program like the C.L.I.M.B. in the same period, and for that reason we excluded it from our post-pilot period.

There are some strengths of our study. Although RCTs are deemed the gold standard to establish evidence of efficacy of a treatment, practitioners tend to find many trial-tested treatments less effective in the real world. Community-based programs do not have strict inclusion/exclusion criteria as RCTs and using quasi-experimental design such as the DID method in our analysis is a potentially valid approach to evaluate real world interventions, provided that the assumptions for the DID methods are carefully considered and deemed plausible. We consider our careful analyses and interpretation of the results as a strength.

Second, we used multiple statistical estimators to quantify the causal effect of interest and the estimates were largely consistent with each other, which was reassuring. Using administrative claims data for research, we frequently find ourselves dealing with many covariates and multiple regression-based analyses tend to mask the differences in patient characteristics between groups. Using clearly defined causal effect of interest, i.e., the average treatment effect on the treated, which answers the specific question: "for patients treated in the pilot sites, was the program a cause for the change in readmission rates?", we do not lose sight of the goal of the evaluation and do not interpret regression coefficients causally when they do not represent causal effects of interest.

Our study has several limitations. Foremost, our outcome and covariates were all based on administrative healthcare data. Although prevention of readmission was an important goal for the insurers, treatments for detox are not limited to the inpatient setting. Compared with measures of relapse in RCTs (e.g., 4 consecutive weeks of opioid use by urine toxicology or self-report, or 7 consecutive days of self-reported use in Lee et al. ${ }^{9}$ ), inpatient admissions do not capture all relapses. However, in the real world, health plans rely on these data to identify target population for quality improvement.

Second, a key untestable assumption for the DID methods is the parallel trend assumption (Figure S2), i.e., the change in 90day readmissions from pre- to post-periods in the control group is a good proxy for the counterfactual change in pilot group had there been no pilot intervention. In our data, the readmission rates in the control group over the pre- to post-pilot periods virtually unchanged. However, in the U.S. population from 2008 to 2016 there was significant decline in the rate of opioidrelated discharges with detoxification services during the hospitalization, ${ }^{4}$ which, although not a direct measure of readmission, presumably was indicative of decline in readmission for detoxification as well. As the treatment modality shifts toward MOUD delivered in an outpatient setting, it is possible that the control group did not reflect the counterfactual change that the pilot group would have experienced. Thus, our DID estimates may be an overestimate of the true effect.

Finally, many patients came to the pilot sites from afar and after leaving the facilities they may not complete the full spectrum of care in the pilot program or benefit from all the services offered. However, since the proportions of patients receiving MAT or outpatient treatment in the pilot sites remained virtually unchanged, we believe the reduction in the intensive outpatient treatment in the pilot group was not due to missing data. As OUD is a chronic disease, patient's willingness to follow the treatment plans is critical for recovery. Finding factors that improve treatment adherence and retention is an important next step in the design for effective intervention in the future.

\section{Conclusions}

Our study used a carefully conceived quasi-experimental design to evaluate a community-based treatment of OUD. The pilot program demonstrated that implementing a chronic care model for OUD in the community was feasible. ${ }^{40}$ Although the small sample size precluded us from drawing a definitive conclusion regarding inpatient detox readmission, we believe more OUD treatment facilities should work with health plans to standardize care for patients with OUD and promote lowering readmission for inpatient withdrawal management.

\section{Abbreviations}


C.L.I.M.B.: community-based life-changing individualized medically assisted evidence-based treatment

OUD: opioid use disorder

DID: difference-in-differences

ASAM: American Society of Addiction Medicine

BCN: Blue Care Network

BCBS: Blue Cross Blue Shield

DRD: difference of risk differences

OR: odds ratio

ROR: ratio of odds ratios

PPO: preferred provider organization

HMO: health maintenance organization

ADI: area deprivation index

COI: childhood opportunity index

SVI: social vulnerability index

RA: regression adjustment

IPW: inverse probability weighted

PS: propensity scores

Cl: confidence interval

RCT: randomized controlled trial

MAT: medically assisted treatment

A-CHESS: Addiction-Center for Health Enablement Support System

LOC: level of care

SUD: substance use disorder

ICD-10-CM: International Classification of Diseases, $10^{\text {th }}$ version, Clinical Modification

\section{Declarations}

\section{- Ethics approval and consent to participate}

The study was approved by the Institutional Review Board of Michigan State University as non-human subject research (STUDY00000846) and no consent to participate was required. 


\section{- Consent for publication}

All authors approved the final version of the manuscript for submission and publication.

\section{- Availability of data and materials}

All data are proprietary and not publicly available.

\section{- Competing interests}

None.

\section{- Funding}

Dr. Luo received an Investigator Initiated Research Program grant (\#002648.MG) from the Blue Cross and Blue Shield of Michigan Foundation.

\section{- Authors' Contributions}

ZL: conceptualization, methodology, writing- original draft preparation, reviewing and editing.

CR: data curation, writing-original draft preparation and editing.

WSP: program implementation, writing--reviewing and editing.

JD: data preparation, writing-reviewing and editing.

CMR: data curation, writing-reviewing and editing.

PHG: data curation, writing-reviewing and editing.

RR: literature summary, writing-reviewing.

WB: program design and implementation, conceptualization, writing-reviewing and editing.

\section{- Acknowledgements}

Michael Hoover, Informatics Delivery Lead (Contractor at BCBSM) assisted with data procurement and secure transfer.

\section{References}

1. Mattson CL. Trends and Geographic Patterns in Drug and Synthetic Opioid Overdose Deaths - United States, 20132019. MMWR Morb Mortal Wkly Rep. 2021;70. doi:10.15585/mmwr.mm7006a4

2. Morgan JR, Wang J, Barocas JA, et al. Opioid overdose and inpatient care for substance use disorder care in Massachusetts. Journal of Substance Abuse Treatment. 2020;112:42-48. doi:10.1016/j.jsat.2020.01.017 
3. Saloner B, Karthikeyan S. Changes in Substance Abuse Treatment Use Among Individuals With Opioid Use Disorders in the United States, 2004-2013. JAMA. 2015;314(14):1515-1517. doi:10.1001/jama.2015.10345

4. Peterson C, Xu L, Florence C, Mack KA. Opioid-related US hospital discharges by type, 1993-2016. Journal of Substance Abuse Treatment. 2019;103:9-13. doi:10.1016/j.jsat.2019.05.003

5. Ballreich J, Mansour O, Hu E, et al. Modeling Mitigation Strategies to Reduce Opioid-Related Morbidity and Mortality in the US. JAMA Netw Open. 2020;3(11):e2023677. doi:10.1001/jamanetworkopen.2020.23677

6. Rieder TN. In Opioid Withdrawal, With No Help In Sight. Health Affairs. 2017;36(1):182-185. doi:10.1377/hlthaff.2016.0347

7. Lagisetty P. The Fine Line Between Doctoring And Dealing. Health Affairs. 2017;36(1):186-189. doi:10.1377/hlthaff.2016.0394

8. Calcaterra SL, Bach P, Chadi A, et al. Methadone Matters: What the United States Can Learn from the Global Effort to Treat Opioid Addiction. J GEN INTERN MED. 2019;34(6):1039-1042. doi:10.1007/s11606-018-4801-3

9. Lee JD, Nunes EV, Novo P, et al. Comparative effectiveness of extended-release naltrexone versus buprenorphine-naloxone for opioid relapse prevention (X:BOT): a multicentre, open-label, randomised controlled trial. Lancet.

2018;391(10118):309-318. doi:10.1016/S0140-6736(17)32812-X

10. Mojtabai R, Mauro C, Wall MM, Barry CL, Olfson M. Medication Treatment For Opioid Use Disorders In Substance Use Treatment Facilities. Health Affairs. 2019;38(1):14-23. doi:10.1377/hlthaff.2018.05162

11. Nosyk B, Li L, Evans E, et al. Utilization and outcomes of detoxification and maintenance treatment for opioid dependence in publicly-funded facilities in California, USA: 1991-2012. Drug Alcohol Depend. 2014;143:149-157. doi:10.1016/j.drugalcdep.2014.07.020

12. Godersky ME, Saxon AJ, Merrill JO, Samet JH, Simoni JM, Tsui JI. Provider and patient perspectives on barriers to buprenorphine adherence and the acceptability of video directly observed therapy to enhance adherence. Addict Sci Clin Pract. 2019;14(1):11. doi:10.1186/s13722-019-0139-3

13. Madras BK, Ahmad NJ, Wen J, et al. Improving Access to Evidence-Based Medical Treatment for Opioid Use Disorder: Strategies to Address Key Barriers Within the Treatment System. NAM Perspectives. Published online April 27, 2020. doi:10.31478/202004b

14. American Society of Addiction Medicine. The ASAM National Practice Guideline for the Use of Medications in the Treatment of Addiction Involving Opioid Use.; 2015. Accessed March 1, 2018. https://www.asam.org/docs/defaultsource/practice-support/guidelines-and-consensus-docs/asam-national-practice-guideline-supplement.pdf? sfvrsn=24\#search="opioid\%20chronic"

15. American Society of Addiction Medicine. The ASAM National Practice Guideline for the Treatment of Opioid Use Disorder: 2020 Focused Update. American Society of Addiction Medicine; 2020:91.

16. Olfson $M$, Wall $M$, Wang S, Crystal S, Blanco $C$. Risks of fatal opioid overdose during the first year following nonfatal overdose. Drug and Alcohol Dependence. 2018;190:112-119. doi:10.1016/j.drugalcdep.2018.06.004

17. Abadie A, Cattaneo MD. Econometric Methods for Program Evaluation. Annu Rev Econ. 2018;10(1):465-503. doi:10.1146/annurev-economics-080217-053402

18. Stuart EA, Huskamp HA, Duckworth $\mathrm{K}$, et al. Using propensity scores in difference-in-differences models to estimate the effects of a policy change. Health Serv Outcomes Res Methodol. 2014;14(4):166-182. doi:10.1007/s10742-014-0123-z

19. Deci EL, Ryan RM. The "What" and "Why" of Goal Pursuits: Human Needs and the Self-Determination of Behavior. Psychological Inquiry. 2000;11(4):227-268. doi:10.1207/S15327965PLI1104_01

20. Gustafson DH, Landucci G, McTavish F, et al. The effect of bundling medication-assisted treatment for opioid addiction with mHealth: study protocol for a randomized clinical trial. Trials. 2016;17:592. doi:10.1186/s13063-016-1726-1

21. Agency for Healthcare Research and Quality. Clinical Classifications Software Refined (CCSR) for ICD-10-CM Diagnoses. Published March 2021. Accessed May 25, 2021. https://www.hcup-us.ahrq.gov/toolssoftware/ccsr/dxccsr.jsp 
22. U.S. Department of Housing and Urban Development. HUD USPS ZIP Code Crosswalk Files. Published 2021. Accessed May 27, 2021. https://www.huduser.gov/portal/datasets/usps_crosswalk.html

23. Wilson R, Din A. Understanding and Enhancing the U.S. Department of Housing and Urban Development's ZIP Code Crosswalk Files. Cityscape. 2018;20(2):277-294.

24. Kind AJH, Buckingham WR. Making Neighborhood-Disadvantage Metrics Accessible - The Neighborhood Atlas. N Engl J Med. 2018;378(26):2456-2458. doi:10.1056/NEJMp1802313

25. University of Wisconsin School of Medicine and Public Health. Area Deprivation Index v2018 Neighborhood Atlas. Published 2021. Accessed May 27, 2021. https://www.neighborhoodatlas.medicine.wisc.edu/download

26. diversitydatakids.org. Child Opportunity Index. Institute for Child, Youth and Family Policy, Heller School for Social Policy and Management, Brandeis University. Published 2021. Accessed May 27, 2021. https://www.diversitydatakids.org/childopportunity-index

27. Centers for Disease Control and Prevention. Social Vulnerability Index, Agency for Toxic Substances and Disease Registry Geospatial Research, Analysis, and Services Program. Published 2021. Accessed May 27, 2021.

https://www.atsdr.cdc.gov/placeandhealth/svi/index.html

28. Austin PC. An Introduction to Propensity Score Methods for Reducing the Effects of Confounding in Observational Studies. Multivariate Behav Res. 2011;46(3):399-424. doi:10.1080/00273171.2011.568786

29. Tan Z. Bounded, efficient and doubly robust estimation with inverse weighting. Biometrika. 2010;97(3):661-682. doi:10.1093/biomet/asq035

30. Chernozhukov V, Chetverikov D, Demirer M, et al. Double/debiased machine learning for treatment and structural parameters. Econom J. 2018;21(1):C1-C68. doi:10.1111/ectj.12097

31. Hirano K, Imbens GW, Ridder G. Efficient Estimation of Average Treatment Effects Using the Estimated Propensity Score. Econometrica. 2003;71(4):1161-1189. doi:10.1111/1468-0262.00442

32. Abadie A, Imbens GW. Bias-Corrected Matching Estimators for Average Treatment Effects. Journal of Business \& Economic Statistics. 2011;29(1):1-11. doi:10.1198/jbes.2009.07333

33. StataCorp. Stata Statistical Software: Release 17. StataCorp LP; 2017.

34. Graham AW, Schultz TK, Mayo-Smith MF, Ries RK, Wilford BB. Principles of Addiction Medicine. American Society of Addiction Medicine; 2003.

35. Morgan JR, Barocas JA, Murphy SM, et al. Comparison of Rates of Overdose and Hospitalization After Initiation of Medication for Opioid Use Disorder in the Inpatient vs Outpatient Setting. JAMA Network Open. 2020;3(12):e2029676. doi:10.1001/jamanetworkopen.2020.29676

36. Nordeck CD, Welsh C, Schwartz RP, et al. Rehospitalization and substance use disorder (SUD) treatment entry among patients seen by a hospital SUD consultation-liaison service. Drug and Alcohol Dependence. 2018;186:23-28. doi:10.1016/j.drugalcdep.2017.12.043

37. Gryczynski J, Nordeck CD, Welsh C, Mitchell SG, O'Grady KE, Schwartz RP. Preventing hospital readmission for patients with comorbid substance use disorder: A randomized trial. Annals of Internal Medicine. 2021;174(7):899-909. doi:10.7326/M20-5475

38. Vilardaga R, Fisher T, Palenski PE, et al. Review of Popularity and Quality Standards of Opioid-Related Smartphone Apps. Curr Addict Rep. 2020;7(4):486-496. doi:10.1007/s40429-020-00344-6

39. Beetham T, Saloner B, Gaye M, Wakeman SE, Frank RG, Barnett ML. Therapies Offered at Residential Addiction Treatment Programs in the United States. JAMA. 2020;324(8):804-806. doi:10.1001/jama.2020.8969

40. McCauley JL, McLelland AT. Treating Addiction Like a Chronic Illness: A Practical Clinical Model. In: The American Psychiatric Association Publishing Textbook Of Substance Use Disorder Treatment. 6th ed. ; 2021:Chapter 7. https://doiorg.proxy2.cl.msu.edu/10.1176/appi.books.9781615373970

\section{Tables}

Page $11 / 20$ 
Table 1. Demographic characteristics, medical claims six months prior to detox in the pre-and post-period 


\begin{tabular}{|c|c|c|c|c|c|c|}
\hline & \multicolumn{3}{|c|}{ Pre-period } & \multicolumn{3}{|c|}{ Post-period } \\
\hline & Control & C.L.I.M.B. & $\begin{array}{l}\text { p- } \\
\text { value } \\
\neq\end{array}$ & Control & C.L.I.M.B. & $\begin{array}{l}\text { p- } \\
\text { value } \\
\ddagger\end{array}$ \\
\hline & $N=1,385$ & $N=318$ & & $N=545$ & $N=195$ & \\
\hline Age category & $\mathrm{N}(\%)$ & $\mathrm{N}(\%)$ & & $\mathrm{N}(\%)$ & $\mathrm{N}(\%)$ & \\
\hline $18-<25$ & $\begin{array}{l}407 \\
(29.4)\end{array}$ & $88(27.7)$ & 0.636 & $\begin{array}{l}154 \\
(28.3)\end{array}$ & $53(27.2)$ & 0.47 \\
\hline $25-<35$ & $\begin{array}{l}364 \\
(26.3)\end{array}$ & $90(28.3)$ & & $\begin{array}{l}147 \\
(27.0)\end{array}$ & $45(23.1)$ & \\
\hline $35-<45$ & $\begin{array}{l}212 \\
(15.3)\end{array}$ & $42(13.2)$ & & $\begin{array}{l}95 \\
(17.4)\end{array}$ & $43(22.1)$ & \\
\hline $45+$ & $\begin{array}{l}402 \\
(29.0)\end{array}$ & $98(30.8)$ & & $\begin{array}{l}149 \\
(27.3)\end{array}$ & $54(27.7)$ & \\
\hline Female & $\begin{array}{l}467 \\
(33.7)\end{array}$ & $96(30.2)$ & 0.228 & $\begin{array}{l}176 \\
(32.3)\end{array}$ & $69(35.4)$ & 0.43 \\
\hline HMO & $\begin{array}{l}245 \\
(17.7)\end{array}$ & $\begin{array}{l}154 \\
(48.4)\end{array}$ & $<0.001$ & $\begin{array}{l}57 \\
(10.5)\end{array}$ & $87(44.6)$ & $<0.001$ \\
\hline \multicolumn{7}{|l|}{ Comorbidity 6 months prior to initial detox } \\
\hline Had no claims & $\begin{array}{l}156 \\
(11.3)\end{array}$ & $34(10.7)$ & 0.770 & $51(9.4)$ & $17(8.7)$ & 0.79 \\
\hline had detox & $78(5.6)$ & $18(5.7)$ & 0.984 & $48(8.8)$ & $15(7.7)$ & 0.63 \\
\hline Had emergency room visits & $\begin{array}{l}708 \\
(51.1)\end{array}$ & $\begin{array}{l}160 \\
(50.3)\end{array}$ & 0.796 & $\begin{array}{l}270 \\
(49.5)\end{array}$ & $89(45.6)$ & 0.35 \\
\hline Had opioid use disorder diagnosis & $\begin{array}{l}677 \\
(48.9)\end{array}$ & $\begin{array}{l}160 \\
(50.3)\end{array}$ & 0.645 & $\begin{array}{l}295 \\
(54.1)\end{array}$ & $\begin{array}{l}102 \\
(52.3)\end{array}$ & 0.66 \\
\hline Substance-related disorders * & $\begin{array}{l}331 \\
(23.9)\end{array}$ & $72(22.6)$ & 0.634 & $\begin{array}{l}174 \\
(31.9)\end{array}$ & $44(22.6)$ & 0.01 \\
\hline Mood disorders $†$ & $\begin{array}{l}550 \\
(39.7)\end{array}$ & $\begin{array}{l}148 \\
(46.5)\end{array}$ & 0.026 & $\begin{array}{l}236 \\
(43.3)\end{array}$ & $84(43.1)$ & 0.96 \\
\hline Alcohol-related disorders & $\begin{array}{l}260 \\
(18.8)\end{array}$ & $68(21.4)$ & 0.287 & $\begin{array}{l}135 \\
(24.8)\end{array}$ & $36(18.5)$ & 0.07 \\
\hline Anxiety/fear/trauma/stressor-related disorders & $\begin{array}{l}585 \\
(42.2)\end{array}$ & $\begin{array}{l}145 \\
(45.6)\end{array}$ & 0.275 & $\begin{array}{l}257 \\
(47.2)\end{array}$ & $84(43.1)$ & 0.33 \\
\hline Suicidal ideation/attempt/intentional self-harm & $\begin{array}{l}130 \\
(9.4)\end{array}$ & $31(9.7)$ & 0.842 & $45(8.3)$ & $12(6.2)$ & 0.35 \\
\hline Neoplasm & $83(6.0)$ & $18(5.7)$ & 0.821 & $32(5.9)$ & $11(5.6)$ & 0.91 \\
\hline Endocrine, nutritional, and metabolic diseases & $\begin{array}{l}418 \\
(30.2)\end{array}$ & $\begin{array}{l}100 \\
(31.4)\end{array}$ & 0.658 & $\begin{array}{l}182 \\
(33.4)\end{array}$ & $62(31.8)$ & 0.68 \\
\hline Diseases of the nervous system & $\begin{array}{l}569 \\
(41.1)\end{array}$ & $\begin{array}{l}120 \\
(37.7)\end{array}$ & 0.273 & $\begin{array}{l}229 \\
(42.0)\end{array}$ & $66(33.8)$ & 0.05 \\
\hline Diseases of the circulatory system & $\begin{array}{l}448 \\
(32.3)\end{array}$ & $92(28.9)$ & 0.238 & $\begin{array}{l}185 \\
(33.9)\end{array}$ & $57(29.2)$ & 0.23 \\
\hline Diseases of the respiratory system & $\begin{array}{l}381 \\
(27.5)\end{array}$ & $83(26.1)$ & 0.611 & $\begin{array}{l}155 \\
(28.4)\end{array}$ & $58(29.7)$ & 0.73 \\
\hline
\end{tabular}




\begin{tabular}{|c|c|c|c|c|c|c|}
\hline Diseases of the digestive system & $\begin{array}{l}350 \\
(25.3)\end{array}$ & $75(23.6)$ & 0.531 & $\begin{array}{l}152 \\
(27.9)\end{array}$ & $38(19.5)$ & 0.02 \\
\hline $\begin{array}{l}\text { Diseases of the musculoskeletal system and } \\
\text { connective tissue }\end{array}$ & $\begin{array}{l}653 \\
(47.1)\end{array}$ & $\begin{array}{l}130 \\
(40.9)\end{array}$ & 0.043 & $\begin{array}{l}238 \\
(43.7)\end{array}$ & $78(40.0)$ & 0.37 \\
\hline Diseases of the genitourinary system & $\begin{array}{l}280 \\
(20.2)\end{array}$ & $62(19.5)$ & 0.773 & $\begin{array}{l}118 \\
(21.7)\end{array}$ & $36(18.5)$ & 0.35 \\
\hline $\begin{array}{l}\text { Injury, poisoning and certain other consequences of } \\
\text { external causes }\end{array}$ & $\begin{array}{l}455 \\
(32.9)\end{array}$ & $\begin{array}{l}119 \\
(37.4)\end{array}$ & 0.120 & $\begin{array}{l}177 \\
(32.5)\end{array}$ & $58(29.7)$ & 0.48 \\
\hline Live in one of the 100 largest metro areas & $\begin{array}{l}965 \\
(69.7)\end{array}$ & $\begin{array}{l}270 \\
(84.9)\end{array}$ & $<0.001$ & $\begin{array}{l}377 \\
(69.2)\end{array}$ & $\begin{array}{l}169 \\
(86.7)\end{array}$ & $<0.001$ \\
\hline Neighborhood characteristics & $\begin{array}{l}\text { Mean } \\
(S D)\end{array}$ & $\begin{array}{l}\text { Mean } \\
(S D)\end{array}$ & & $\begin{array}{l}\text { Mean } \\
(\mathrm{SD})\end{array}$ & $\begin{array}{l}\text { Mean } \\
(S D)\end{array}$ & \\
\hline Mean ADI state rank & $\begin{array}{l}48.4 \\
(21.6)\end{array}$ & $\begin{array}{l}44.8 \\
(23.9)\end{array}$ & 0.009 & $\begin{array}{l}51.3 \\
(22.3)\end{array}$ & $\begin{array}{l}44.0 \\
(24.4)\end{array}$ & $<0.001$ \\
\hline Mean ADI national rank & $\begin{array}{l}59.8 \\
(19.4)\end{array}$ & $\begin{array}{l}57.1 \\
(22.1)\end{array}$ & 0.033 & $\begin{array}{l}61.1 \\
(20.3)\end{array}$ & $\begin{array}{l}55.6 \\
(23.4)\end{array}$ & $<0.01$ \\
\hline Mean childhood opportunity index & $\begin{array}{l}54.1 \\
(20.8)\end{array}$ & $\begin{array}{l}56.0 \\
(23.4)\end{array}$ & 0.149 & $\begin{array}{l}51.7 \\
(21.6)\end{array}$ & $\begin{array}{l}57.8 \\
(24.2)\end{array}$ & $<0.01$ \\
\hline Mean SVI socioeconomic score & $\begin{array}{l}44.9 \\
(20.2)\end{array}$ & $\begin{array}{l}42.0 \\
(22.4)\end{array}$ & 0.022 & $\begin{array}{l}47.0 \\
(20.5)\end{array}$ & $\begin{array}{l}39.5 \\
(22.9)\end{array}$ & $<0.001$ \\
\hline Mean SVI household/disability score & $\begin{array}{l}52.8 \\
(18.2)\end{array}$ & $\begin{array}{l}48.0 \\
(18.7)\end{array}$ & $<0.001$ & $\begin{array}{l}54.1 \\
(17.7)\end{array}$ & $\begin{array}{l}46.0 \\
(19.5)\end{array}$ & $<0.001$ \\
\hline Mean SVI minority/language score & $\begin{array}{l}31.8 \\
(17.7)\end{array}$ & $\begin{array}{l}35.3 \\
(16.8)\end{array}$ & 0.001 & $\begin{array}{l}35.0 \\
(19.0)\end{array}$ & $\begin{array}{l}35.6 \\
(17.3)\end{array}$ & 0.66 \\
\hline Mean SVI housing/transportation score & $\begin{array}{l}39.9 \\
(14.6)\end{array}$ & $\begin{array}{l}36.0 \\
(14.7)\end{array}$ & $<0.001$ & $\begin{array}{l}42.3 \\
(15.9)\end{array}$ & $\begin{array}{l}34.1 \\
(14.0)\end{array}$ & $<0.001$ \\
\hline
\end{tabular}

*. Including cannabis-, sedative-, stimulant- hallucinogen- or inhalant-related substances

†. Including depressive disorders, bipolar disorders, and other specified mood disorders

‡. $\mathrm{p}$-values are based on chi-square tests for categorical variables and $t$-tests for continuous variables

C.L.I.M.B. = Community-based Life-changing Individualized Medically assisted evidence-Based treatment

$A D I=$ area deprivation index

SVI = social vulnerability index

$\mathrm{SD}=$ standard deviation

Table 2. Standardized difference (SD) between C.L.I.M.B. and comparison in the pre- and post-period respectively 


\begin{tabular}{|c|c|c|c|c|}
\hline & \multicolumn{2}{|c|}{ Pre-period } & \multicolumn{2}{|c|}{ Post-period } \\
\hline & $\begin{array}{l}\text { Raw } \\
\text { SD }\end{array}$ & $\begin{array}{l}\text { Weighted } \\
\text { SD }\end{array}$ & $\begin{array}{l}\text { Raw } \\
\text { SD }\end{array}$ & Weighted SD \\
\hline \multicolumn{5}{|l|}{ Age category } \\
\hline $18-<25$ & 0.038 & -0.078 & 0.024 & 0.019 \\
\hline $25-<35$ & -0.046 & 0.025 & 0.089 & -0.198 \\
\hline $35-<45$ & 0.059 & -0.047 & -0.119 & 0.105 \\
\hline $45+$ & -0.039 & 0.090 & -0.008 & 0.086 \\
\hline Female & 0.075 & -0.099 & -0.066 & 0.168 \\
\hline $\mathrm{HMO}$ & -0.757 & -0.040 & -0.933 & -0.060 \\
\hline \multicolumn{5}{|l|}{ Comorbidity 6 months prior to initial detox } \\
\hline Had no claims & 0.018 & 0.021 & 0.022 & -0.083 \\
\hline had detox & -0.001 & -0.030 & 0.040 & -0.046 \\
\hline Had emergency room visits & 0.016 & -0.038 & 0.078 & -0.070 \\
\hline Had opioid use disorder diagnosis & -0.029 & 0.025 & 0.037 & -0.120 \\
\hline Substance-related disorders * & 0.030 & -0.051 & 0.206 & -0.161 \\
\hline Mood disorders † & -0.139 & 0.143 & 0.005 & -0.017 \\
\hline Alcohol-related disorders & -0.066 & 0.028 & 0.150 & -0.129 \\
\hline Anxiety/fear/trauma/stressor-related disorders & -0.068 & 0.032 & 0.082 & -0.078 \\
\hline Suicidal ideation/attempt/intentional self-harm & -0.012 & -0.018 & 0.079 & -0.187 \\
\hline Neoplasm & 0.014 & 0.002 & 0.010 & 0.005 \\
\hline Endocrine, nutritional, and metabolic diseases & -0.028 & 0.062 & 0.034 & -0.055 \\
\hline Diseases of the nervous system & 0.068 & -0.041 & 0.167 & -0.223 \\
\hline Diseases of the circulatory system & 0.073 & -0.039 & 0.101 & -0.135 \\
\hline Diseases of the respiratory system & 0.032 & -0.061 & -0.029 & -0.007 \\
\hline Diseases of the digestive system & 0.039 & -0.037 & 0.193 & -0.192 \\
\hline Diseases of the musculoskeletal system and connective tissue & 0.126 & -0.103 & 0.074 & -0.094 \\
\hline Diseases of the genitourinary system & 0.018 & -0.015 & 0.079 & -0.026 \\
\hline $\begin{array}{l}\text { Injury, poisoning and certain other consequences of external } \\
\text { causes }\end{array}$ & -0.097 & 0.081 & 0.059 & -0.063 \\
\hline Live in one of the 100 largest metro areas & -0.344 & 0.302 & -0.404 & 0.274 \\
\hline \multicolumn{5}{|l|}{ Neighborhood characteristics } \\
\hline Mean ADI state rank $\ddagger$ & 0.163 & 0.022 & 0.317 & -0.130 \\
\hline Mean ADI national rank & 0.132 & 0.029 & 0.261 & -0.138 \\
\hline Mean childhood opportunity index & -0.090 & -0.078 & -0.274 & 0.093 \\
\hline Mean SVI socioeconomic score $\S$ & 0.142 & 0.058 & 0.355 & -0.143 \\
\hline
\end{tabular}

Page 15/20 


\begin{tabular}{|lllll|}
\hline Mean SVI household/disability score & 0.265 & 0.019 & 0.443 & -0.258 \\
\hline Mean SVI minority/language score & -0.202 & 0.168 & -0.037 & 0.123 \\
\hline Mean SVI housing/transportation score & 0.267 & -0.068 & 0.529 & -0.136 \\
\hline
\end{tabular}

*. Including cannabis-, sedative-, stimulant- hallucinogen- or inhalant-related substances

†. Including depressive disorders, bipolar disorders, and other specified mood disorders

C.L.I.M.B. = Community-based Life-changing Individualized Medically assisted evidence-Based treatment

$\mathrm{SD}=$ standardized difference, comparison group minus treatment group divided by the pooled standard error

ADI: area deprivation index

SVI: social vulnerability index

Table 3. Readmission rate in pre- and post-period and C.L.I.M.B. and comparison groups

\begin{tabular}{|c|c|c|c|c|c|c|c|c|c|c|c|c|}
\hline & \multicolumn{4}{|l|}{ Pre-period } & \multicolumn{4}{|c|}{ Post-period } & \multicolumn{4}{|c|}{ Treatment Effect } \\
\hline & C.L.I.M.B. & Control & RD & OR & C.L.I.M.B. & Control & $\mathrm{RD}$ & OR & DRD & $\begin{array}{l}95 \% \\
\mathrm{Cl} *\end{array}$ & ROR & $\begin{array}{l}95 \% \\
\mathrm{Cl} *\end{array}$ \\
\hline $\begin{array}{l}\text { ATET } \\
\text { Unadjusted }\end{array}$ & 16.4 & 10.0 & 6.3 & 1.75 & 11.8 & 10.1 & 1.7 & 1.19 & $\overline{4} .6$ & $\begin{array}{l}{[-} \\
11.2 \\
2.0]\end{array}$ & 0.68 & $\begin{array}{l}{[0.37} \\
1.27]\end{array}$ \\
\hline $\begin{array}{l}\text { ATET } \\
\text { Adjusted }\end{array}$ & 16.4 & 9.3 & 7.1 & 1.95 & 11.8 & 11.1 & 0.6 & 1.08 & $\overline{6.4}$ & $\begin{array}{l}{[-} \\
14.2, \\
1.1]\end{array}$ & 0.72 & $\begin{array}{l}{[0.38,} \\
1.37]\end{array}$ \\
\hline $\begin{array}{l}\text { ATET AIPW } \\
\text { Lasso }\end{array}$ & 16.4 & 10.3 & 6.0 & 1.70 & 11.8 & 11.8 & 0.04 & 1.00 & $\overline{6} .0$ & $\begin{array}{l}{[-} \\
13.8, \\
1.6]\end{array}$ & 0.59 & $\begin{array}{l}{[0.28,} \\
1.22]\end{array}$ \\
\hline ATET IPW & 16.4 & 9.5 & 6.9 & 1.87 & 11.8 & 14.7 & $\overline{2} .9$ & 0.78 & $\overline{9} .8$ & $\begin{array}{l}{[-} \\
21.4 \\
0.03]\end{array}$ & 0.42 & $\begin{array}{l}{[0.17,} \\
1.11]\end{array}$ \\
\hline $\begin{array}{l}\text { ATET } \\
\text { IPWRA }\end{array}$ & 16.4 & 9.3 & 7.1 & 1.91 & 11.8 & 11.7 & 0.1 & 1.01 & $\overline{6} .9$ & $\begin{array}{l}{[-} \\
18.5, \\
0.6]\end{array}$ & 0.53 & $\begin{array}{l}{[0.19,} \\
1.12]\end{array}$ \\
\hline $\begin{array}{l}\text { ATET } \\
\text { NNMATCH }\end{array}$ & 16.4 & 11.6 & 4.7 & 1.49 & 11.8 & 16.1 & $\overline{4} .3$ & 0.70 & $\overline{9} .0$ & $\begin{array}{l}{[-} \\
18.3 \\
5.5]\end{array}$ & 0.47 & $\begin{array}{l}{[0.20,} \\
2.00]\end{array}$ \\
\hline $\begin{array}{l}\text { ATET } \\
\text { PSMATCH }\end{array}$ & 16.4 & 10.4 & 6.0 & 1.69 & 11.8 & 23.1 & $\overline{11.2}$ & 0.46 & $\overline{17.3}$ & $\begin{array}{l}{[-} \\
22.5, \\
3.5]\end{array}$ & 0.26 & $\begin{array}{l}{[0.14,} \\
1.72]\end{array}$ \\
\hline
\end{tabular}

C.L.I.M.B. = Community-based Life-changing Individualized Medically assisted evidence-Based treatment

$\mathrm{RD}=$ risk difference

$\mathrm{OR}=$ odds ratio

DRD = difference of risk differences

$\mathrm{ROR}=$ ratio of odds ratios 
$\mathrm{Cl}=$ confidence interval

ATET = average treatment effect on the treated

AIPW = augmented inverse - probability weighting

IPW = inverse probability weighting

IPWRA = inverse probability weighted regression adjustment

NNMATCH $=$ nearest - neighbor matching

PSMATCH $=$ propensity - score matching

* 95\% Cl percentile-based bootstrap 1,000 times

Table 4. Proportions of patients receiving post-detox treatments

\begin{tabular}{|lllllll|}
\hline & Pre-period & & \multicolumn{3}{c|}{ Post-period } \\
& Control & C.L.I.M.B. & p-value* & Control & C.L.I.M.B. & p-value* \\
& $\mathrm{N}=1,385$ & $\mathrm{~N}=318$ & & $\mathrm{~N}=545$ & $\mathrm{~N}=195$ & \\
\hline Medication assisted treatment & $390(28.2)$ & $131(41.2)$ & $<.001$ & $153(28.1)$ & $71(36.4)$ & 0.030 \\
\hline Intensive outpatient treatment & $303(21.9)$ & $115(36.2)$ & $<.001$ & $146(26.8)$ & $46(23.6)$ & 0.382 \\
\hline Outpatient treatment & $688(49.7)$ & $208(65.4)$ & $<.001$ & $270(49.5)$ & $124(63.6)$ & 0.001 \\
\hline
\end{tabular}

C.L.I.M.B. = Community-based Life-changing Individualized Medically assisted evidence-Based treatment

* p-values are based on chi-square tests.

Table 5. Intensive outpatient treatment services use in pre- and post-period and C.L.I.M.B. and comparison groups 


\begin{tabular}{|c|c|c|c|c|c|c|c|c|c|c|c|c|}
\hline & \multicolumn{4}{|l|}{ Pre-period } & \multicolumn{4}{|c|}{ Post-period } & \multicolumn{4}{|c|}{ Treatment Effect } \\
\hline & C.L.I.M.B. & Control & RD & OR & C.L.I.M.B. & Control & RD & OR & DRD & $\begin{array}{l}95 \% \\
\mathrm{Cl} *\end{array}$ & ROR & $\begin{array}{l}95 \% \\
\mathrm{Cl} *\end{array}$ \\
\hline $\begin{array}{l}\text { ATET } \\
\text { Unadjusted }\end{array}$ & 36.2 & 21.9 & 14.3 & 2.02 & 23.6 & 26.8 & $\overline{3.2}$ & 0.84 & $\overline{17.5}$ & $\begin{array}{l}{[-} \\
26.3, \\
- \\
8.3]\end{array}$ & 0.42 & $\begin{array}{l}{[0.26,} \\
0.66]\end{array}$ \\
\hline $\begin{array}{l}\text { ATET } \\
\text { Adjusted }\end{array}$ & 36.2 & 23.3 & 12.9 & 1.91 & 23.6 & 24.4 & $\overline{0} .7$ & 0.96 & $-\overline{13.6}$ & $\begin{array}{l}{[-} \\
23.7, \\
- \\
4.4]\end{array}$ & 0.42 & $\begin{array}{l}{[0.26,} \\
0.67]\end{array}$ \\
\hline $\begin{array}{l}\text { ATET AIPW } \\
\text { Lasso }\end{array}$ & 36.2 & 18.9 & 17.2 & 2.43 & 23.6 & 22.2 & 1.4 & 1.08 & $-\overline{15.9}$ & $\begin{array}{l}{[-} \\
25.3, \\
- \\
5.5]\end{array}$ & 0.45 & $\begin{array}{l}{[0.27,} \\
0.78]\end{array}$ \\
\hline ATET IPW & 36.2 & 19.0 & 17.2 & 2.42 & 23.6 & 19.7 & 3.9 & 1.26 & $\overline{13.3}$ & $\begin{array}{l}{[-} \\
24.6, \\
- \\
2.3]\end{array}$ & 0.52 & $\begin{array}{l}{[0.28,} \\
0.98]\end{array}$ \\
\hline $\begin{array}{l}\text { ATET } \\
\text { IPWRA }\end{array}$ & 36.2 & 19.0 & 17.2 & 2.41 & 23.6 & 19.7 & 3.9 & 1.26 & $\overline{13.3}$ & $\begin{array}{l}{[-} \\
25.2, \\
- \\
3.0]\end{array}$ & 0.52 & $\begin{array}{l}{[0.26,} \\
0.97]\end{array}$ \\
\hline $\begin{array}{l}\text { ATET } \\
\text { NNMATCH }\end{array}$ & 36.2 & 22.2 & 14.0 & 1.99 & 23.6 & 24.1 & $\overline{0} .5$ & 0.97 & $\overline{14.6}$ & $\begin{array}{l}{[-} \\
33.4, \\
- \\
2.3]\end{array}$ & 0.49 & $\begin{array}{l}{[0.18,} \\
0.98]\end{array}$ \\
\hline $\begin{array}{l}\text { ATET } \\
\text { PSMATCH }\end{array}$ & 36.2 & 22.0 & 14.2 & 2.01 & 23.6 & 22.1 & 1.5 & 1.09 & $\overline{12.6}$ & $\begin{array}{l}{[-} \\
28.8, \\
- \\
1.5]\end{array}$ & 0.54 & $\begin{array}{l}{[0.21,} \\
1.37]\end{array}$ \\
\hline
\end{tabular}

C.L.I.M.B. = Community-based Life-changing Individualized Medically assisted evidence-Based treatment

$\mathrm{RD}=$ risk difference

$\mathrm{OR}=$ odds ratio

$\mathrm{DRD}=$ difference of risk differences

$\mathrm{ROR}=$ ratio of odds ratios

$\mathrm{Cl}=$ confidence interval

ATET = average treatment effect on the treated

AIPW = augmented inverse - probability weighting

IPW = inverse probability weighting

IPWRA = inverse probability weighted regression adjustment

NNMATCH = nearest - neighbor matching

PSMATCH = propensity-score matching 


\section{Figures}

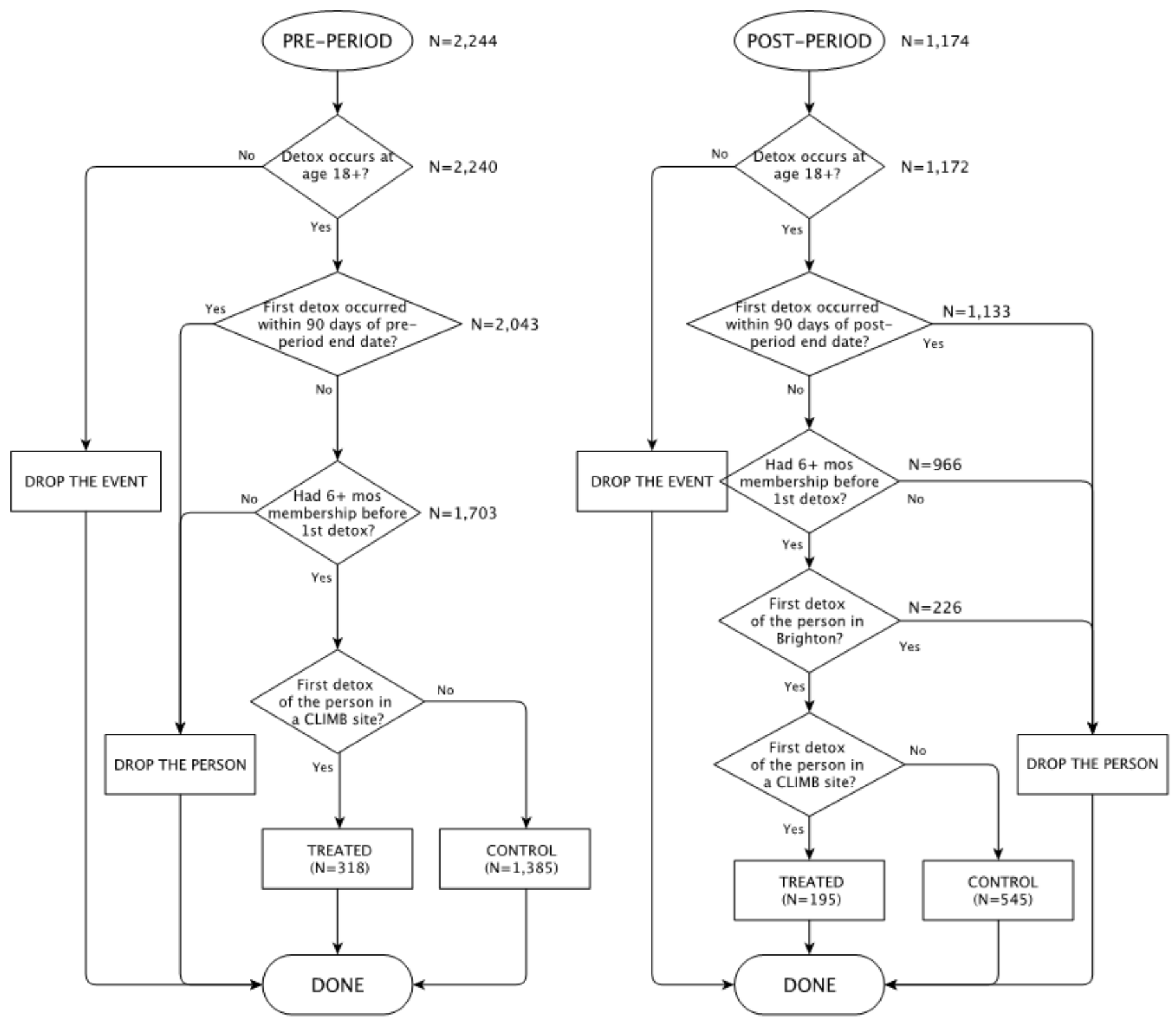

Figure 1

\section{Patient selection criteria}



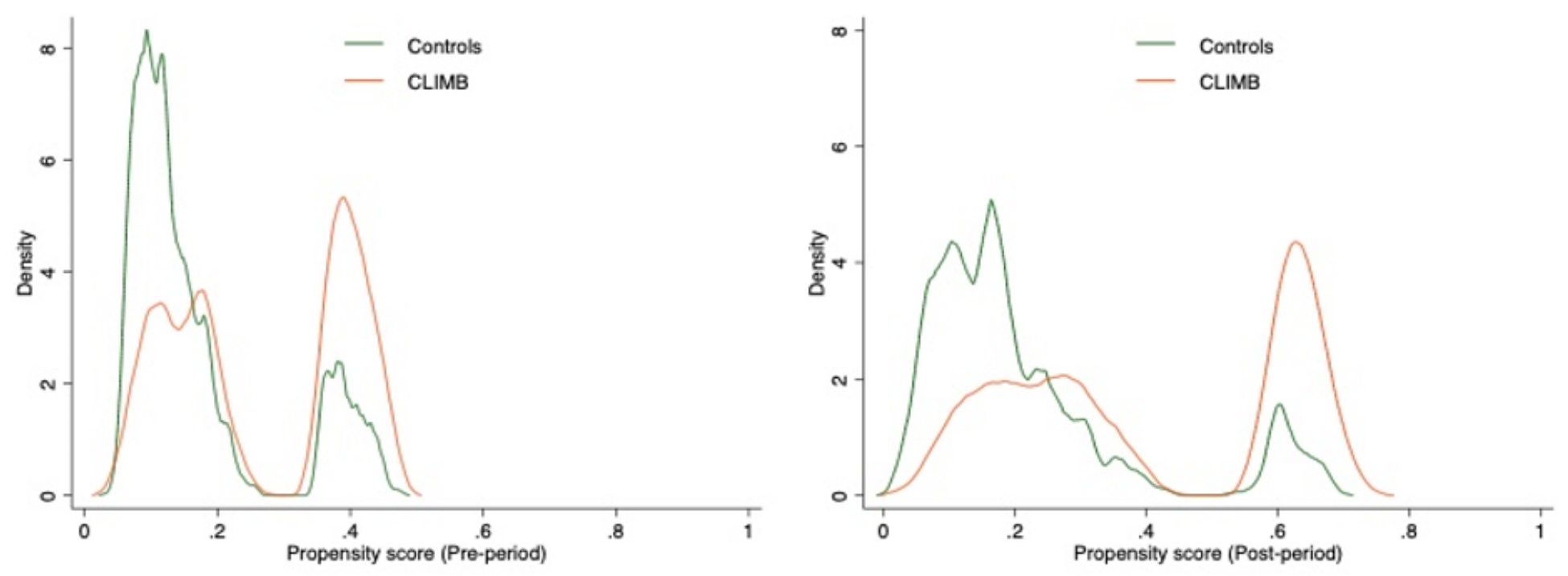

Figure 2

Propensity scores for participating in the pilot program in pre-and post-periods

\section{Supplementary Files}

This is a list of supplementary files associated with this preprint. Click to download.

- Supplementalmaterials.docx 